\title{
Craniovertebral anomalies associated with pituitary gland duplication
}

\author{
I. Milić, M. Samardžić, I. Djorić, G. Tasić, V. Djulejić, S. Marinković \\ Neuroanatomy and Gross Anatomy, Institute of Anatomy, Faculty of Medicine, University of Belgrade, Serbia \\ [Received 27 January 2015; Accepted 10 September 2015]
}

Background: An extremely rare occurrence of the pituitary gland duplication inspired us to examine in detail the accompanying craniovertebral congenital anomalies in a patient involved.

Materials and methods: T1-wighted magnetic resonance imaging (MRI) was performed, as well as the multislice computerised tomography (MSCT) and MSCT angiography in our patient, as well as in a control group of 10 healthy subjects. Results: In a 20-year-old male a double pituitary gland was identified, as well as hypothalamic enlargement, tuberomamillary fusion and hamartoma. In addition, the patient also showed a duplicated hypophyseal fossa and posterior clinoid processes, notch of the upper sphenoid, prominent inner relief of the skull, inverse shape of the foramen magnum, third occipital condyle, partial aplasia of the anterior and posterior arches of the atlas with a left arcuate foramen, duplication of the odontoid process and the C2 body, and fusion of the C2-C4 and T12-L1 vertebrae. The MSCT angiography presented a segmental dilatation of both vertebral arteries and the A2 segment of the anterior cerebral artery, as well as a duplication of the basilar artery.

Conclusions: This patient is unique due to complex craniovertebral congenital anomalies associated with a duplication of the pituitary gland. (Folia Morphol 2015; 74, 4: 524-531)

Key words: atlas aplasia, craniovertebral anomalies, vertebrae fusion, pituitary duplication, third occipital condyle, odontoid duplication

\section{INTRODUCTION}

The craniovertebral junction in the narrow sense comprises the right and left occipital condyles, atlas and axis $[16,31,47]$. Most of the anomalies of these bony elements occur very infrequently $[1-3,6$, $8-10,12,15,17,19,24,25,27,28,35,36,38-40$, $46,48,50,51,54,55]$. Duplication of the pituitary gland is an extremely rare event $[4,5,7,11,20,23$, $26,30,34,37,42,44,45,49,52,53]$. Because of that, we decided to examine in detail a patient with those two types of the congenital anomalies. In order to achieve this, we performed magnetic resonance imaging (MRI), multislice computerised tomography (MSCT) and MSCT angiography, as well as standard radiological morphometric methods. In addition, 10 volunteers were also examined by the MSCT apparatus in order to provide normal measurements of the relevant structures.

\section{MATERIALS AND METHODS}

Following admission of a 20-year-old patient to our Clinic of Neurosurgery, T1-wighted MRI was per-

Address for correspondence: S. Marinković, MD, PhD, Professor of Neuroanatomy and Gross Anatomy, Institute of Anatomy, Faculty of Medicine, University of Belgrade, Dr. Subotić 4/2, 11000 Belgrade, Serbia, e-mail: mocamarinkovic@med.bg.ac.rs 
formed in a 1.5 tesla Philips Intera apparatus. Two days later MSCT was performed in a Siemens Somatom Definition AS 128-slice scanner (rotation time $0.5 \mathrm{~s}$, pitch 0.5 , slice thickness $0.6 \mathrm{~mm}, 120-140 \mathrm{kV}$ interval, manual $260 \mathrm{~mA}$, noise index 3). This type of the scanner has the lowest level of the $\mathrm{X}$-radiation. The MSCT cerebral angiography was performed as well, using Ultravist 370 as a contrast (bolus $100 \mathrm{~mL}$, flow of contrast $4 \mathrm{~mL} / \mathrm{s}$ ). Multiplanar reconstruction and volume rendering were made of the skull, spine and blood vessels.

The control group consisted of 10 healthy subjects ( 6 males and 4 females) aged 19-39 (mean 31.8) years. The written consent of each person was obtained. The whole procedure was approved by the authorities of the Clinic of Neurosurgery and the Ethics Committee of the University Clinical Centre. All the volunteers underwent examination in the same MSCT apparatus. Linear measurements of certain parameters were performed in 3 planes (axial, coronal and sagittal) using standard software installed in the MSCT equipment.

\section{RESULTS}

Our patient will be presented first, and then the 10 subjects within the control group.

\section{Case report}

A 20-year-old man was admitted to the Clinic of Neurosurgery due to an intracranial tumour and pituitary gland duplication diagnosed in a local hospital by the MRI examination of the head and brain. The patient was previously examined because of the hypogonadism, an initial gynecomastia and delayed puberty. Two years previously, cryptorchism was diagnosed and a bilateral orchiopexy was performed. Because of a low level of testosterone $(0.18 \mathrm{ng} / \mathrm{mL})$, the patient started to receive a supplementary endocrine therapy. The other endocrinological and biochemical analyses were normal, as well as his karyotype (46XY). He was born vaginally at 39 week to a healthy 24-year-old mother. His family history is unremarkable.

The patient was tall $(182.3 \mathrm{~cm})$ and obese (body weight $105 \mathrm{~kg}$ ) with a slight gynecomastia and moderate hypogonadism. He had a broad forehead, slightly prominent superciliary arches, progenia, a high palate, and short neck with some rotational difficulties. The examination showed no neurological symptoms or signs. The psychological testing obtained a general IQ of 74 .

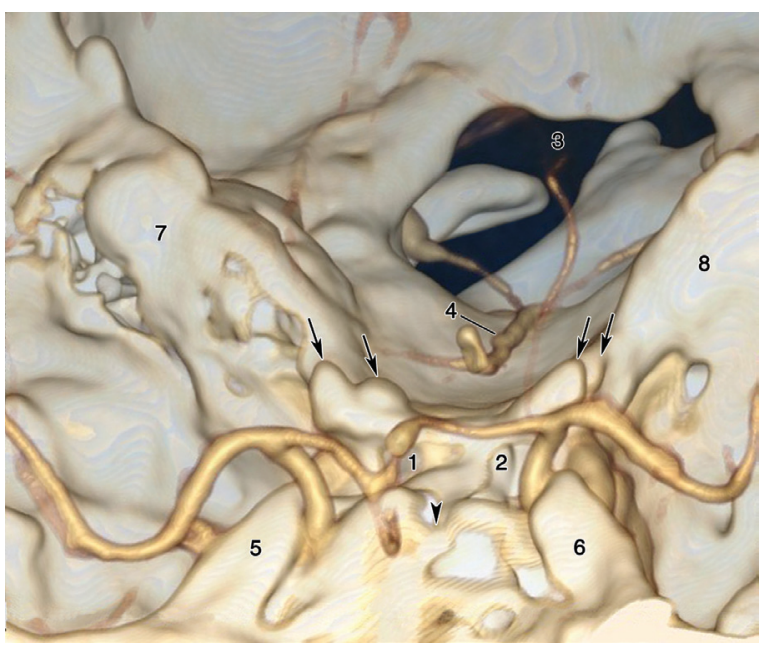

Figure 1. Superior, and slightly anterior and left view of the sellar region with two hypophyseal fossae (1 and 2) in a 3-dimensional reconstruction of the multislice computerised tomography angiograms. Note a notch (arrowhead) in the region of the tuberculum sellae, as well as the dorsum sellae with two posterior clinoid processes (arrows) on each side. Relatively close to them are the A1 segments of the right and left anterior cerebral arteries; 3 foramen magnum; $4-$ basilar artery on the clivus; 5 and $6-$ right and left anterior clinoid processes, close to which is the corresponding internal carotid artery; 7 and 8 - right and left petrous part of the temporal bone.

The T1-weighted MRI of the brain showed 2 pituitary glands, each of them with its own pituitary stalk. Of the other possible anomalies of the brain, only some alterations of the hypothalamus were noticed. Namely, the region of the median eminence, i.e. the posterior part of the tuber cinereum and infundibulum, was thicker than usual and was fused with the mammillary bodies. Just left to the fusion, a small suprasellar parasagittal mass was noticed, measuring $12 \mathrm{~mm} \times 10 \mathrm{~mm}$ in size. The mass, which was radiologically described as a hamartoma, slightly displaced the left internal carotid artery.

The MSCT examination presented 2 hypophyseal fossae in the sellar region, a bony notch at the level of the tuberculum sellae, and a broad dorsum sellae with a duplication of both right and left posterior clinoid processes (Fig. 1). The relief of the tabula interna of the skull interior was very expressed. The foramen magnum was oval in shape, and measured $35.6 \mathrm{~mm}$ in the sagittal diameter and $39.1 \mathrm{~mm}$ in the transverse diameter (Table 1).

The atlas (C1) showed, firstly, a partial aplasia of the posterior arch in its middle part (Fig. 2). The gap between the remnants of the right and left parts of that arch measured $26.1 \mathrm{~mm}$. The right and left 
Table 1. Measurements [mm] of the bones and foramina: range (mean)

\begin{tabular}{|c|c|c|c|c|c|}
\hline \multirow[t]{3}{*}{ Subjects } & \multirow[t]{3}{*}{ Foramen magnum } & \multirow{3}{*}{$\begin{array}{l}\text { Atlas (transverse } \\
\text { diameter) }\end{array}$} & \multicolumn{3}{|c|}{ Odontoid process } \\
\hline & & & \multirow[t]{2}{*}{ Height } & \multicolumn{2}{|c|}{ Diameter } \\
\hline & & & & Superior & Inferior \\
\hline \multirow[t]{2}{*}{ Patient } & $35.6 \times 39.1$ & 91.9 & 8.6 & 8.1 & 14.5 \\
\hline & & & 7.7 & 7.6 & 14.7 \\
\hline \multirow[t]{2}{*}{ Volunteers } & $35.3 \times 28.0$ & $75.3-90.4(82.5)$ & $14.4-19.4(16.9)$ & $7.8-12.1(10.1)$ & $11.4-16.1(13.4)$ \\
\hline & $\begin{array}{c}40.1 \times 32.8 \\
(37.3 \times 30.2)\end{array}$ & & & & \\
\hline
\end{tabular}

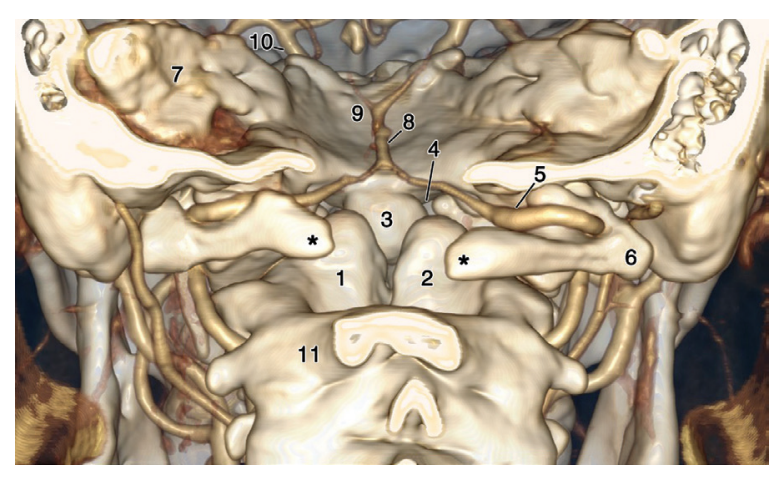

Figure 2. Posterior view of the craniovertebral junction. Note the aplasia of the posterior arch (between the two asterisks) of the atlas, a duplication ( 1 and 2) of the odontoid process, and a separate bone (3) merged with the anterior rim (4) of the foramen magnum; 5 - dilatation of the vertebral artery between the atlas and the occipital bone; 6 - transverse process of the atlas; 7 - petrous part of the left temporal bone; 8 - basilar artery on the clivus; 9 - dorsum sellae; 10 - left internal carotid artery; 11 - left lamina of the axis, close to its spinous process (cut). Note the fused laminae of the C2-C4 vertebrae.

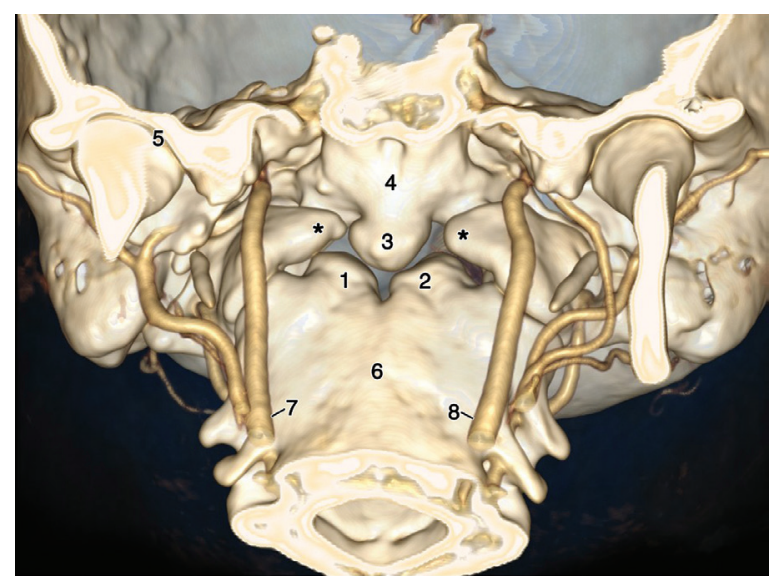

Figure 3. Anterior and slightly inferior view of the craniovertebral junction presenting a duplication (1 and 2) of the odontoid process and a separate bone structure (3) which is continuous with the basilar part of the occipital bone (4). Note the aplasia (between the two asterisks) of the anterior arch of the atlas; 5 - right temporomandibular joint; 6 - fused bodies of the C2-C4 vertebrae; 7 and $8-$ right and left internal carotid arteries. lateral masses normally articulated with the occipital condyles above and the facets of the axis below. Both transverse foramina were incomplete in their anterior part. The longest transverse diameter of the atlas measured $91.9 \mathrm{~mm}$ (Table 1). Finally, a partial aplasia of the middle part of the anterior arch was present as well (Fig. 3). The gap between the remnants of the arch measured $22.7 \mathrm{~mm}$.

The odontoid process (dens) of the axis (C2) was duplicated. The left process was a little bit higher $(8.6 \mathrm{~mm})$ than the right one $(7.7 \mathrm{~mm})$ (Table 1$)$. The superior (cranial) transverse diameter, just below the apex, of the left process measured $8.1 \mathrm{~mm}$, and of the right one $7.6 \mathrm{~mm}$, whereas the inferior (caudal) transverse diameter, at the level of the dens base, was $14.5 \mathrm{~mm}$ of the left process and $14.7 \mathrm{~mm}$ of the right process (Table 1). The diameter of the cleft between the two processes (Figs. 2, 3) measured $3.7 \mathrm{~mm}$ in the upper part, and $3.0 \mathrm{~mm}$ in the basal part.

The cleft narrowed and continued through the body of the axis. This vertical cleft, from the level of the dens tip to the C3 body, measured $23.7 \mathrm{~mm}$ in length. Finally, the axis, C3 and C4 vertebrae were completely fused together (Figs. 2, 3). Such a fusion was also observed between the T12 and L1 vertebrae.

A separate bone, located above and partially in front of the duplicated odontoid process, was merged with the middle part of the anterior rim of the foramen magnum (Figs. 2, 3). This osseous junction measured $10.8 \mathrm{~mm}$ in a transverse direction. The maximum transverse diameter of the bone had a value of $12.9 \mathrm{~mm}$, and its maximum sagittal diameter reached the value of $10.7 \mathrm{~mm}$.

The MSCT angiography (Figs. 2, 4) showed some cerebral arteries of an uneven diameter, hypoplasia or "hyperplasia" of some other vessels, and an early bifurcation of the basilar artery. Thus, a dilatation 


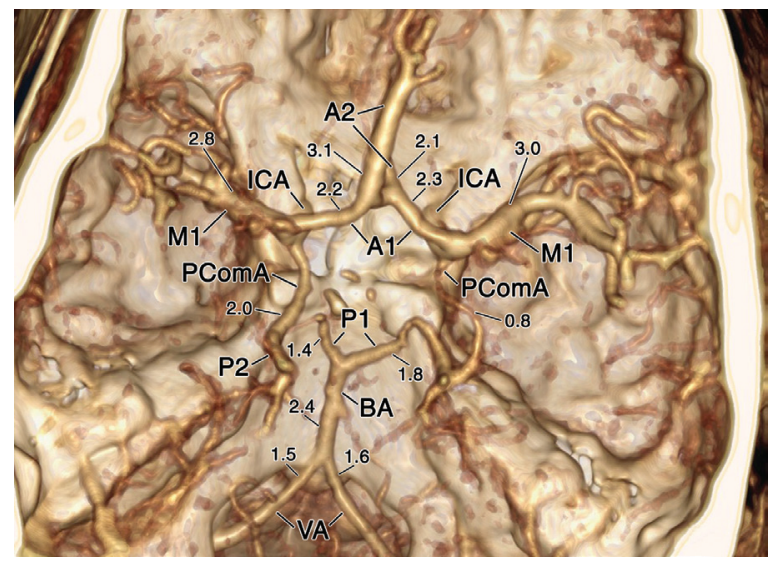

Figure 4. Superior, and slightly posterior and right view of the main cerebral arteries at the base of the skull in a 3-dimensional reconstruction of the cerebral angiograms; VA — right and left vertebral arteries; BA — basilar artery; P1 — proximal segments of the left and right posterior cerebral arteries; P2 - distal segment of the left posterior cerebral artery; PComA — right and left posterior communicating arteries; ICA — right and left internal carotid arteries; $\mathrm{M} 1$ - proximal segment of the right and left middle cerebral arteries; $\mathrm{A} 1$ and $\mathrm{A} 2$ - proximal and distal segments of the anterior cerebral arteries. Note the values of the vascular diameters in millimetres.

of the extradural vertebral artery on both sides was observed (Fig. 2), which measured $3.4 \mathrm{~mm}$ and $3.3 \mathrm{~mm}$ in diameter, respectively, whereas the intradural (medullary) segment of both arteries was much thinner (Fig. 4). These 2 arteries formed a short basilar artery (only $20.6 \mathrm{~mm}$ in length), which presented an early bifurcation, i.e. a duplication. Mild hypoplasia of the left P1 segment was present, as well as "hyperplasia" of the left posterior communicating artery, which was continuous with the ipsilateral P2 segment. A local dilatation of the $\mathrm{A} 2$ segment of the left anterior cerebral artery was observed, which measured $3.1 \mathrm{~mm}$ in size (Fig. 4). The vascular diameters are presented in Figure 4.

\section{Control group}

In order to compare the obtained radiological data and measurements in our patient with normal parameters, 10 healthy volunteers underwent the MSCT examination. We measured in these subjects the sagittal and transverse diameters of the foramen magnum (mean, $37.3 \mathrm{~mm} \times 30.2 \mathrm{~mm}$ ), the transverse diameter of the atlas ( $82.5 \mathrm{~mm}$ on average), the height of the odontoid process (mean $16.9 \mathrm{~mm}$ ), and its superior (mean $10.1 \mathrm{~mm}$ ) and inferior transverse diameters (mean $13.4 \mathrm{~mm}$ ) (Table 1).
In addition, a 29-year-old male showed an incomplete left transverse foramen of the atlas, whereas a 19-year-old female presented an asymptomatic aplasia of the middle part of the posterior arch of the atlas.

\section{DISCUSSION}

We distinguished in this section a presentation of the craniovertebral anomalies, and a description of a double pituitary gland with the accompanying brain alterations.

\section{Craniovertebral anomalies}

The infrequent congenital anomalies may affect any of the main parts of the craniovertebral junction. They are manifested in several ways.

Firstly, they can be expressed as hypoplasia of the clivus or the occipital condyles with atlantoaxial subluxation $[25,46]$. In some other patients a narrow foramen magnum was observed, as well as a clivus-odontoid articulation [32, 33]. A specific bone, the so-called median or third condyle, occurs very rarely [17]. The foramen magnum, which was not measured in other reports, was oval in our patient. Its diameters are inversed when compared to the measurements within the volunteers' group, i.e. the foramen had a shorter sagittal than a transverse diameter.

As regards the atlas, its agenesis, partial aplasia, hypoplasia or a cleft of the C1 posterior arch can appear, or the agenesis or aplasia of the anterior arch $[1,2,6,8,9,24,27,28,35,36,38,51]$. Occurrence of the supernumerary facets of the atlas is also possible, as well as its partial fusion with the odontoid or with the anterior rim of the foramen magnum, or an incomplete transverse foramen [18, 25, 39, 46]. The latter event is called the arcuate foramen [50]. If there is a combination of the partial aplasia of both arches, such a C1 vertebra is known as a bipartite atlas [24], which mainly consists of the 2 lateral masses and transverse processes. In the case of an arch absence or its partial aplasia, a bony defect is bridged by dense fibrous tissue [27].

The anomalies affecting the $\mathrm{C} 2$ vertebra can be manifested as an absence of its laminae [8] or the presence of supernumerary facets, as well as a cleft or a double body $[30,39]$. Certain changes in the region of the odontoid process may also occur: its aplasia [1, 19], hypoplasia [10, 12, 48, 54, 55], fusion with the $\mathrm{C} 1$ anterior arch or with the clivus [18], as 
well as cleft, bifurcation [43] or duplication [15, 30]. Occasionally, basilar invagination occurs, or os odontoideum or os terminale close to the dens $[1,3,12$, $13,17,28,46,55]$.

The adjacent vertebrae can be partially or completely fused $[33,55]$. These congenital fusions of the cervical vertebrae are consistent with the Klippel-Feil anomaly, Rubinstein-Taybi syndrome and some other disorders [16, 21, 28, 30, 40, 55].

Most of the mentioned craniovertebral anomalies are so uncommon, that they were often published separately as case reports in renowned international journals. Two of them were accidentally revealed in our group of healthy volunteers, i.e. partial aplasia of the posterior arch of the atlas, as well as an arcuate foramen of the same vertebra.

In $55 \%$ of the patients with a double pituitary gland, at least one of the above mentioned craniovertebral anomalies could be found, e.g. hypoplasia, cleft or duplication of the odontoid process, the $\mathrm{C} 2$ body duplication or widened C1 arch [30, 43, 45, 52]. In some cases, a cleft of another cervical vertebra was seen, as well as a duplication of the cervical vertebral bodies. In other patients, partial or complete fusion affected various cervical vertebrae: $\mathrm{C2}-\mathrm{C} 3, \mathrm{C} 3-\mathrm{C} 5$ or C2-C5 [28, 40, 45]. In 1 patient thoracolumbo-sacral rachischisis was reported [36]. Our patient presented a complete fusion of the $\mathrm{C} 2-\mathrm{C} 4$ vertebrae. As a consequence, he had a shortness of the neck with some limitation of the lateral rotation. In addition, the patient showed fusion of the T12 and L1 vertebrae.

In our patient with a double pituitary, we did not find a single craniovertebral anomaly, but a combination of several of them: partial aplasia of the $\mathrm{C} 1$ posterior and anterior arches, that is a bipartite atlas, and a left arcuate foramen of the atlas, then duplication of the odontoid and body of the $\mathrm{C} 2$, the third occipital condyle, and fusion of the $\mathrm{C} 2-\mathrm{C} 4$ and $\mathrm{T} 12$ and L1 vertebrae. As for the bipartite atlas, it is produced by a disorder of the embryonic ossification centres, one of which forms the anterior arch and the other two create the posterior arch and the lateral masses [38]. The bipartite atlas in our patient, whose right and left halves were completely separated (Figs. 2, 3), had a transverse diameter longer than in the volunteers' group $(91.1 \mathrm{~mm}$ in the patient, compared with a maximum $90.4 \mathrm{~mm}$ in healthy subjects). The latter is most likely the reason for the mentioned inverse oval shape of the foramen magnum in our patient. Finally, his broad sella showed a double hypophyseal fossa, a superior sphenoid notch and duplication of the posterior clinoid processes (Fig. 1).

A bone, which was located superior and anterior to the dens, was merged with the middle part of the anterior rim of the foramen magnum, i.e. with the basion region (Figs. 2, 3). This bone, which was named as the median or third condyle, is actually a remnant of the occipital vertebra [17]. Embrylogically, the hypocentrum of the 4 th occipital sclerotome (proatlas) normally develops into the anterior tubercle of the clivus, whereas its centrum forms the apical cap of the dens $[3,17]$. The rostral ventral neural arch takes part in the formation of the anterior rim of the foramen magnum, the occipital condyles and third condyle, whilst the dorsocaudal part of the neural arch partially forms the arches of the atlas and its lateral masses. The first cervical (C1) sclerotome gives rise to the rest of the dens and atlas, whereas the $\mathrm{C} 2$ sclerotome forms the largest part of the axis body and its arch. It is obvious that disorders of all the mentioned sclerotomes were expressed in our patient.

The odontoid process in our patient was duplicated. The upper and lower diameters of the two were smaller than those in the group of volunteers (Table 1). Their height was shorter as well, i.e. $8.1 \mathrm{~mm}$ on average, compared to $16.1 \mathrm{~mm}$ in volunteers. According to some authors $[3,15]$, the odontoid process has 2 foetal ossification centres on each side of the midline, which fuse in the postnatal period, i.e. by 1 year in age. A delay in fusion results in a cleft which separates the two halves of dens. This cleft also passed virtually through the whole thickness of the axis body in our patient.

Most of the described craniovertebral anomalies are usually discovered as an incidental asymptomatic finding, as was the case with our patient $[9,27,36]$. In spite of this, all of the anomalies have a great clinical significance for several reasons. Firstly, some of them can still cause radicular nerves compression or myelopathy, for instance a hypoplastic C1 vertebra or partial absence of the posterior arch with a consecutive stenosis of the spinal canal, then fused cervical vertebrae with compression to the spinal cord [27, 35, 38, 40], etc. Secondly, the neurological symptoms and signs most often appear only following a spinal trauma in these persons [30, 33, 45]. Thirdly, knowledge of these anomalies is important to avoid an erroneous diagnosis of a bone fracture, luxation, osteolysis or instability of the craniovertebral region $[2,14,38]$. Finally, the anomaly finding is important in order to take certain surgical protection measures [24, 37]. 
As for the skull, brachycephaly or microcephaly was sometimes present in patients with a double pituitary $[45,53]$. Within the skull, duplication of the sella was noticed, or a broad sella with 2 hypophyseal fossae (like in our patient), or cleft of the body of the sphenoid or basi-sphenoid [5, 41, 42, 45]. We also noticed in our patient a very expressed inner relief of the skull bones, which is like "gyral impressions" in shape.

\section{Double pituitary gland}

Pituitary duplication is an extremely rare event. According to some reports, from 1880 until 2011 only 38 such patients were reported [30]. The pituitary duplication can be associated with certain face abnormalities: a bifid or double tongue, cleft lips or palate, macrostomia, supernumerary teeth, micrognathia or retrognathia, palatine dermoid, epignathus, pharyngeal teratoma, hypertelorism, broad forehead, and an altered shape of the auricle [5, 20, $23,26,42,45,49,52]$.

The described craniofacial anomalies or duplications, i.e. median cleft face syndrome, can also be seen in persons without a double pituitary gland $[22,43]$. In some of them, even a double nose can be present, as well as a third orbit [22]. Our patient presented only mild face anomalies, i.e. a broad forehead, somewhat prominent superciliary arches, low positioned auricles, and progenia.

In addition to the face anomalies in patients with a double pituitary, certain changes were sometimes noticed in various organs or body parts: a short neck, torticollis, an absent thyroid isthmus, cardiac anomalies including ventricular septal defect and transposition of great vessel, agenesis of the hemidiaphragm, congenital diaphragmatic hernia, 11 pairs of ribs, urinary abnormalities, renal agenesis or a kidney hypertrophy, colorectal atresia, etc. [30, 45, 49].

The pituitary duplication was usually associated with a double pituitary stalk and infundibulum, and rarely with a duplication of the anterior 3rd ventricle. In 1 case even a triplication of the pituitary gland was revealed [29]. Some patients with duplication present precocious puberty $[11,52,53]$. On the contrary, some other individuals, like our patient, show hypogonadism and delayed sexual development [45].

As regards the brain structures, hypothalamic enlargement was noticed occasionally, as well as tuberomamillary fusion [7, 29, 34, 45, 53]. In some patients, hypoplasia, or a partial or total agenesis of the corpus callosum were revealed, then agenesis of the anterior commissure or the septum pellucidum, absence of the olfactory bulb and/or tract, broad optic nerves or chiasm, hydrocephalus or ventricular enlargement, then duplication of the anterior 3rd ventricle, Sylvian aqueduct or mammillary bodies, as well as third cerebral peduncle, hypoplastic or broad pons, hypoplastic cerebellum, clival encephalocoele, Dandy-Walker syndrome, and cleft or partial duplication of the spinal cord $[4,5,7,20,23,30,34,37,45,49]$.

Of all the mentioned brain anomalies and neoplastic changes, our patient showed hypothalamic enlargement and its fusion with the mammillary bodies, as well as a suprasellar hamartoma. The latter pathologic alteration, with a similar parahypothalamic location, was found in several of the reported patients with pituitary duplication [30].

Some neurological symptoms and signs can be manifested in those patients, but in many of them, including our patient, the neurological deficits were absent $[30,45]$. The psychological status of the patients is either normal or in the domain of mental retardation. Our patient had a general IQ of 74 .

The cerebral vasculature in our patient comprised several hypoplastic or "hyperplastic" arterial segments, but also an early bifurcation, i.e. duplication, of the basilar artery, as was noticed in some other patients $[7,23,44,49]$. The latter anomaly seems to be a characteristic features in patients with the pituitary duplication [44]. Like us, some authors also found a segmental dilatation of the distal anterior cerebral artery, i.e. the pericallosal vessel [7], but we also noticed a dilatation of the extradural segment of both vertebral arteries (Fig. 2). As regards the congenital cerebrovascular malformations, the arterial aneurysms were not found, but only an arteriovenous malformation was present in 1 patient $[7,45]$.

The cause and mechanism of the pituitary duplication, facial and craniovertebral anomalies are still being debated. Partial twinning is supposed, as well as prenatal teratogen exposure, a variant of the median cleft face syndrome, and splitting of the notochord during embryonic development $[30,45]$.

\section{CONCLUSIONS}

Our patient seems to be unique in that he has complex craniovertebral anomalies, i.e. such a number and combination of individual anomalies which have not been reported so far in persons with a duplication of the pituitary gland. In addition, the 3rd occipital condyle, 
to our knowledge, has never been described in these patients. On the other hand, most of the associated face and cerebral anomalies were absent in our patient.

\section{ACKNOWLEDGEMENTS}

This work was supported by grant No. 175061 from the Ministry of Science, Serbia. We are very grateful to Mrs. Elza Holt for reviewing the English text of our manuscript

\section{REFERENCES}

1. Ahmed R, Traynelis VC, Menezes AH (2008) Fusions at the craniovertebral junction. Child Nerv Syst, 24: 1209-1224.

2. Alvarez Caro F, Pumarada Prieto PM, Alvarez Berciano F (2008) Congenital defect of the atlas and axis. A cause of misdiagnose when evaluating an acute neck trauma. Am J Emerg Med, 26: 840.e1-e2.

3. Arvin B, Fournier-Gosselin MP, Fehlings MG (2010) Os odontoideum: etiology and surgical management. Neurosurgery, 66 (3 suppl.): A22-A31.

4. Bagherian V, Graham M, Gerson LP, Armstrong DL (1984) Double pituitary glands with partial duplication of facial and forebrain structures with hydrocephalus. Comput Radiol, 8: 203-210.

5. Bale PM, Reye RD (1976) Epignathus, double pituitary and agenesis of corpus callosum. J Pathol, 120: 161-164.

6. Bliemel C, Kuehl H, Ruchholtz S, Kühne CA (2009) Partial aplasia of the atlas in a child. Unfallchirurg, 112: 513-516.

7. Burke M, Zinkovsky S, Abrantes MA, Riley W (2000) Duplication of the hypophysis. Pediatr Neurosurg, 33: 95-99.

8. Chau AM, Wong JH, Mobbs RJ (2009) Cervical myelopathy associated with congenital $\mathrm{C} 2 / 3$ canal stenosis and deficiencies of the posterior arch of the atlas and laminae of the axis: case report and review of the literature. Spine, 34: E886-E891.

9. Currarino G, Rollins N, Diehl JT (1994) Congenital defects of the posterior arch of the atlas: a report of seven cases including an affected mother and son. Am J Neuroradiol, 15: 249-254.

10. Davis D, Gutierrez FA (1977) Congenital anomaly of the odontoid in children. A report of four cases. Child Brain, 3: 219-229.

11. de Penna GC, Pimenta MP, Drummond JB, Sarquis M, Martins JC, de Campos RC, Dias EP (2005) Duplication of the hypophysis associated with precocious puberty: presentation of two cases and review of pituitary embryogenesis. Arq Bras Endocrinol Metabol, 49: 323-327.

12. El Asri AC, Akhaddar A, Gazzaz M, Okacha N, Boulhroud O, Baallal $\mathrm{H}$, Belfquih $\mathrm{H}$, Belhachmi A, Mandour C, El Mostarchid B, Boucetta M (2010). Dynamic CT scan of the craniovertebral junction: a role in the management of os odontoideum. Neurol Neurochir Pol, 44: 603-608.

13. Fielding W, Hensinger RN, Arbor A, Hawkins RJ (1980) Os odontoideum. J Bone Joint Surg Am, 62: 376-383.

14. Ganau M, Spinelli R, Tacconi L (2013) Complex developmental abnormality of the atlas mimicking a Jefferson fracture: diagnostic tips and tricks. J Emerg Trauma Shock, 6: 47-49.
15. Garant M, Oudjhane K, Sinsky A, O'Gorman AM (1997) Duplicated odontoid process: plain radiographic and CT appearance of a rare congenital anomaly of the cervical spine. Am J Neuroradiol, 18: 1719-1720.

16. Garrett M, Consiglieri G, Kakarla UK, Cang SW, Dickman CA (2010) Occipitoatlantal dislocation. Neurosurgery, 66 (3 suppl.): A48-A55.

17. Goel A, Shah A (2010) Unusual bone formation in the anterior rim of foramen magnum: cause, effect and treatment. Eur Spine J, 19 (suppl. 2): S162-S164.

18. Gupta S, Phadke RV, Jain VK (1993) C1-C2 block vertebra with fusion of anterior arch of atlas and the odontoid. Australas Radiol, 37: 95-96.

19. Gurney JW (1986) Absent dens on submentovertex view of the skull: new sign of an abnormal odontoid. Can Assoc Radiol J, 37: 38-39.

20. Hamon-Kérautret M, Ares GS, Demondion X, Rouland V, Francke JP, Pruvo JP (1998) Duplication of the pituitary gland in a newborn with median cleft face syndrome and nasal teratoma. Pediatr Radiol, 28: 290-292.

21. Hankinson TC, Anderson RCE (2010) Craniovertebral junction abnormalities in Down syndrome. Neurosurgery, 66 (3 suppl.): A32-A38.

22. Hähnel S, Schramm P, Hassfeld S, Steiner HH, Seitz A (2003) Craniofacial duplication (diprosopus): CT MR imaging, and MR angiography indings. Case report. Radiology, 226: 210-213.

23. Hori A (1983) A brain with two hypophyses in median cleft face syndrome. Acta Neuropathol, 59: 150-154.

24. Hu Y, Ma W, Xu R (2009) Transoral osteosynthesis C1 as a function-preserving option in the treatment of bipartite: atlas deformity: a case report. Spine, 34: E418-E421.

25. likko E, Tikkakoski T, Pyhtinen J (1998) The helical three-dimensional CT in the diagnosis of torticollis with occipitocondylar hypoplasia. Eur J Radiol, 29: 55-60.

26. Ilina EG, Laziuk GI (1989) A new case of the "double hypophysis-multiple congenital developmental defect" complex. Tsitol Genet, 23: 45-46.

27. Klimo P JR, Blumenthal DT, Couldwell WT (2003) Congenital partial aplasia of the posterior arch of the atlas causing myelopathy: case report and review of the literature. Spine, 28: E224-228.

28. Lampropoulou-Adamidou K, Athanassacopoulos M, Karampinas PK, Vlamis J, Korres DS, Pneumaticos SG (2013). Congenital variations of the upper cervical spine and their importance in preoperative diagnosis. A case report and a review of the literature. Eur J Orthop Surg Traumatol, 23 (suppl. 1): S101-S105.

29. Manara R, Citton V, Rossetto M, Padoan A, D'Avella D (2009) Hypophyseal triplication: case report and embryologic considerations. Am J Neuroradiol, 30: 1328-1329.

30. Manjila S, Miller EA, Vadera S, Goel RK, Khan FR, Crowe C, Geertman RT (2012) Duplication of the pituitary gland associated with multiple blastogenesis defects: Duplication of the pituitary gland (DPG)-plus syndrome. Case report and review of literature. Surg Neurol Int, 3: 23-35.

31. Martin MD, Bruner HJ, Majman DJ (2010) Anatomic and biomechanical considerations of the craniovertebral junction. Neurosurgery, 66 (3 suppl.): A2-A6. 
32. Menezes AH, VanGilder JC, Graf CJ, McDonnell DE (1980) Craniocervical abnormalities. A comprehensive surgical approach. J Neurosurg, 53: 444-455.

33. Michie I, Clark M (1968) Neurological syndromes associated with cervical and craniocervical anomalies. Arch Neurol, 18: 241-247.

34. Mutlu H, Paker B, Bunes N, Emektar A, Keceli M, Kantarci M (2004) Pituitary duplication associated with oral dermoid and corpus callosum hypogenesis. Neuroradiology, 46: 1036-1038.

35. Phan N, Marras C, Midha R, Rowed D (1998) Cervical myelopathy caused by hypoplasia of the atlas: two case reports and review of the literature. Neurosurgery, 43: 629-633.

36. Quinteiro Antolin T, Castellano Romero I, Yáñze Calvo J (2012) Aplasia of the posterior arches of the atlas: a presentation of 2 cases. Rev Esp Cir Ortop Traumatol, 56: 381-384.

37. Roessmann U (1984) Duplication of the pituitary gland and spinal cord. Arch Pathol Lab Med, 109: 518-520.

38. Sabuncuoglu H, Ozdogan S, Karadag D, Kaynak ET (2011) Congenital hypoplasia of the posterior arch of the atlas: case report and extensive review of the literature. Turk Neurosurg, 21: 97-103.

39. Salunke P, Futane S, Sharma M, Sahoo S, Kovilapu U, Khandelwal NK (2015) "Pseudofacets" or "supernumerary facets" in congenital atlanto-axial dislocation: boon or bane? Eur Spine J, 24: 80-87.

40. Samartzis D, Kalluri P, Herman J, Lubicky JP, Shen FH (2008) 2008 young investigator award: The role of congenitally fused cervical segments upon the space available for the cord and associated symptoms in Klippel-Feil patients. Spine, 33: 1442-1450.

41. Shah P, Likeman M, Munro-Davies L (2007) Bradycardia in minor trauma: don't be slow on the uptake! Emerg Med J, 24: e13.

42. Shah S, Pereira JK, Becker CJ, Roubal SE (1997) Duplication of pituitary gland. J Comput Assist Tomogr, 21: 459-461.

43. Shen W, Cui J, Chen J, Ji Y, Zou J, Chen H, Xiongzheng M (2013) Partial midfacial duplication. J Craniofac Surg, 24: 934-936.
44. Shroff M, Blaser S, Jay V, Chitayat D, Armstrong D (2003) Basilar artery duplication associated with pituitary duplication: a new finding. Am J Neuroradiol, 24: 956-961.

45. Slavotinek A, Parisi M, Heike C, Hing A, Huang E (2005) Craniofacial defects of blastogenesis: Duplication of pituitary with cleft palate and oropharyngeal tumors. Am J Med Genet A, 35: 13-20.

46. Smith JS, Shaffrey Cl, Abel MF, Menezes AH (2010) Basilar invagination. Neurosurgery, 66 (3 suppl.): A39-A47.

47. Steinmetz MP, Mroz TE, Benzel EC (2010) Craniovertebral junction: biomechanical considerations. Neurosurgery, 66 (3 suppl.): A7-A12.

48. Stevens CA, Pearce RG, Burton EM (2009) Familial odontoid hypoplasia. Am J Med Genet A, 49A: 1290-1292.

49. Tagliavini F, Pilleri G (1986) Mammillo-hypophyseal duplication (diplo-mammillo-hypophysis). Acta Neuropathol, 69: 38-44.

50. Travan L, Saccheri P, Sabbadini G, Crivellato E (2011) Bilateral arcuate foramen associated with partial defect of the posterior arch of the atlas in a medieval skeleton: case report and review of the literature. Looking backward to go forward. Surg Radiol Anat, 33: 495-500.

51. Tsuang FY, Chen JY, Wang YH, Lai DM (2011). Neurological picture. Occipitocervical malformation with atlas duplication. J Neurol Neurosurg Psychiatry, 82: 1101-1102.

52. Vieira TC, Chinen RN, Ribeiro MR, Nogueira RG, Abucham J (2007) Central precocious puberty associated with pituitary duplication and midline defects. J Pediatr Endocrinol Metab, 20: 1141-1144.

53. Vittore CP, Murray RA, Martin LS (2005) Case 79: pituitary duplication. Radiology, 234: 411-414.

54. Westermeyer RR (2003) Odontoid hypoplasia presenting as torticollis: a discussion of its significance. J Emerg Med, 24: 15-18.

55. Yamamoto T, Kurosawa K, Masuno M, Okuzumi S, Kondo S, Miyama S, Okamoto N, Aida N, Nishimura G (2005) Congenital anomaly of cervical vertebrae is a major complication of Rubinstein-Taybi syndrome. Am J Med Genet A, 135: $130-133$. 